\title{
Pierre Muller
}

Centre de recherches administratives

Fondation nationale des sciences politiques-Paris

\section{La política agrícola francesa o la crisis de una política sectorial}

SUMARIO: LAS POLITICAS PUBLICAS COMO MEDIACION. La gestión de la relación global-sectorial. El referente de las políticas públicas. EMERGENCIA Y DESARROLLO DE UNA POLITICA SECTORIAL. Un referente de mantenimiento. El desarrollo de un corporativismo agrícola. 1958: un cambio de referente. La recomposición de las relaciones Estado-profesión. 1981: la mediación inacabada. LA POLITICA AGRICOLA FRANCESA ANTE EL CAMBIO: LA CRISIS DE LA APROXIMACION SECTORIAL. Una lógica lineal. La transformación de las sociedades rurales francesas. Tres rupturas. Crisis del liderazgo. La reforma de la política comunitaria. El medio rural como espacio empresarial. ¿Políticas sectoriales o políticas locales? LA POLITICA AGRICOLA Y LA CRISIS DEL MODELO FRANCES DE ADMINISTRACION PUBLICA.

A pesar de la relativa especificidad de su objeto, de sus métodos y de las personas afectadas, la historia de la política agrícola francesa es una buena ilustración del interés del análisis de las políticas públicas para comprender las transformaciones del Estado moderno. En efecto, esta política pone de relieve de manera casi caricaturesca el paso de una lógica tradicional basada en el territorio a una lógica típica de las sociedades modernas basadas en una aproximación sectorial a los problemas económico-sociales. Estudiar la evolución de la política agrícola permite, pues, conocer mejor esta transformación fundamental de las sociedades industriales, así como los límites con los que se encuentra en la actualidad. Pero antes de abordar la política agrícola propiamente dicha es preciso definir los principales conceptos de nuestro modelo de análisis de las poíticas públicas (JOBERT, MULLER, 1987; Mu. LLER, 1990). 


\section{LAS POLITICAS PUBLICAS COMO MEDIACION}

¿Qué es una política pública? Charles O. JONES insiste en la polisemia del término, que es utilizado en contextos muy diferentes (JoNES, 1970). Por esta razón, los autores a menudo proponen una definición amplia de una política pública, lo que permite introducirse en el tema sin fijar demasiado, de forma previa, sus contornos. Este es el caso de la definición de Jean-Claude, THOENIG en el Traité de Science Politique y que constituye una buena síntesis de la abundante literatura existente, principalmente anglosajona: «Una política pública se presenta bajo la forma de un programa de acción de una o varias autoridades públicas o gubernamentales (THOENIG, 1985; ver también MÉNY, THOENIG, 1989). Este enfoque se adecúa perfectamente a la orientación pragmática que a menudo adoptan los analistas políticos. Muchos autores más o menos acaban identificando política pública y programa de acción gubernamental. La ventaja de estas definiciones es que permiten fijar un objetivo de investigación relativamente concreto: la política agrícola, la política urbana o la política de transportes como conjunto de programas de las instituciones de Gobierno en los respectivos campos de la agricultura, del urbanismo o de los transportes.

Presentan, en cambio, el inconveniente de no aportar nada sobre la génesis social de las políticas públicas, que debe ser investigada en los orígenes de las sociedades industriales, particularmente a través del paso de la territorialidad a la sectorialidad como forma dominante de organización social. Es por ello que proponemos ver a una política pública como un proceso de mediación social, en la medida que el objeto de cada politica pública son los desajustes que pueden producirse entre un sector y otros sectores, o aun entre un sector y la sociedad global. Diremos, por tanto, que el objeto de una política pública es la gestión de una «relación global/sectorial».

\section{La gestión de la relación global-sectorial}

Cada sector se reproduce al transformarse y al modificar sus relaciones con los demás sectores. Así, el desarrollo del sector del automóvil entrañó una serie de efectos sobre los demás sectores: necesidad de construir carreteras y autopistas, de crear sistemas para el cuidado de los accidentados, de reformar el código penal y el código de circulación, de adaptar las estrategias de aprovisionamiento energético. Las políticas de construcción de carreteras, de lucha contra el alcoholismo al conducir, de desarrollo de sistemas de ayuda médica urgente y de traumatología, de promoción del ahorro de energía son otras tan- 
tas tentativas de regulación de las relaciones entre el sector del automóvil y los demás sectores. Podíamos afirmar lo mismo en relación con las políticas de vivienda, dado que la política de vivienda tiene por objetivo ajustar las performances (los outputs) del sector de la vivienda con los outputs de otros sectores. Por ejemplo, el éxodo rural (producto de la modernización del sector agrícola) provoca una modificación importante de la demanda de vivienda y modifica las condiciones de reproducción del sector de la vivienda.

La relación global/sectorial es a la vez el objeto de las políticas públicas (el problema que se intenta solucionar al poner en práctica las políticas) y la variable-clave que determina las condiciones de elaboración de una política. Así, es en función del lugar que ocupa el sector del automóvil en la sociedad que será elaborada una política destinada precisamente a modificar las relaciones que el sector del automóvil mantiene con los demás sectores. Lo propio de una sociedad sectorial es generar permanentemente una infinidad de desfases y de desajustes entre los sectores donde los modos de reproducción chocan constantemente. De ahí la obsesión por el «cambio», la «modernización» o la «adaptación» de estas sociedades. En efecto, de una forma u otra, el objeto de las políticas consiste siempre en frenar o acelerar la transformación del sector del que se ocupan. Su desarrollo provoca inevitablemente otros desfases que habrá que gestionar a su vez... y así sucesivamente.

Existe, pues, política pública cuando una autoridad política local o nacional persigue, por medio de un programa de acción coordinado, modificar el entorno cultural, social o económico de los actores sociales que se ballan sujetos en general a una lógica sectorial. A partir de aquí, toda política puede descomponerse en tres procesos fundamentales:

- Se trata, en primer lugar, de un intento de gestionar el lugar, el rol y la función del sector afectado en función de la sociedad global o en función de otros sectores.

- Esta relación global/sectorial no puede transformarse en objeto de intervención pública más que en función de la imagen construida por los mismos actores. Es esta imagen, que denominamos referente de una politica pública (1) que designa el conjunto de normas o imágenes de referencia en función de las cuales son definidos los criterios de intervención del Estado así como los objetivos de la política pública considerada.

- En esas condiciones, una fase fundamental de la investigación consistirá en determinar cuál es el actor (o grupo de actores) encargado de la operación de construcción o transformación

(1) Nota del traductor: «référentiel d'une politique publique» en francés. 
del referente de una política pública. En efecto, este actor, que llamaremos mediador ocupará una posición estratégica dentro del conjunto del sistema de decisión examinado.

Podemos resumir estas tres características a través del esquema siguiente:

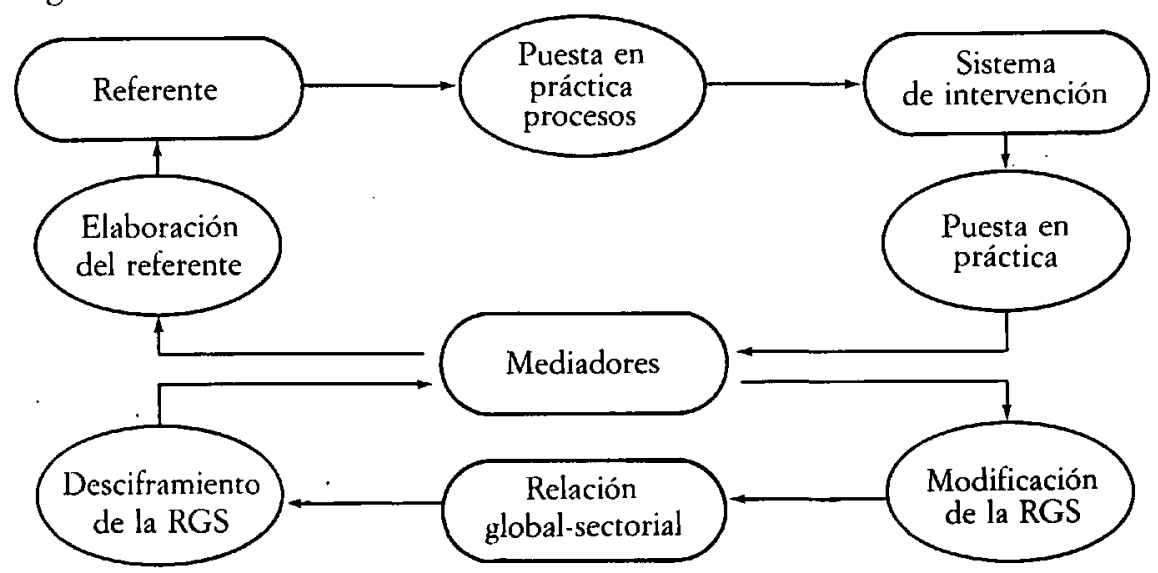

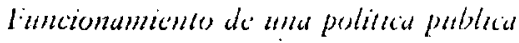

\section{El referente de las politicas públicas}

Elaborar una política pública consiste, pues, en construir una representación, una imagen de la realidad sobre la que queremos intervenir. Es en relación con esta imagen congnoscitiva que los actores organizan su percepción del sistema, confrontan sus soluciones y definen sus propuestas de acción: es el referente de una política. El núcleo duro de esta representación del sistema está constituido por una cierta concepción del lugar y del rol del sector en cuestión dentro de la sociedad. Por ejemplo, la definición de una política de defensa nacional depende estrechamente de la imagen y de la percepción de cuál sea el principal riesgo y del lugar que se entiende deben ocupar las Fuerzas Armadas en la nación. Dependiendo de que se trate de defender las fronteras del país, de asumir un cierto lugar en el concierto mundial o de difundir un mensaje revolucionario, la representación del rol del Ejército variará y en el mismo sentido variará el referente de la política de defensa.

En cada caso, el referente de una política está constituido por un conjunto de normas prescriptivas que dan un sentido a un programa político al definir los criterios de elección y las formas de selección de los objetivos. De acuerdo con lo dicho anteriormente, se trata de un proceso cognoscitivo en el que la función consistirá en comprender lo real limitando, a su vez, su propia complejidad. El problema que se 
plantea entonces es saber cómo las diferentes imágenes de referencia, cuya articulación no aparece siempre de forma evidente, encuentran un mínimo de coherencia para constituir un referente único. El proceso de construcción de un referente se puede descomponer en tres operaciones concomitantes:

- Una operación de selección de las informaciones en función de una determinada estructura de percepción de la realidad. En este sentido, construimos un modelo de explicación de los cambios que afectan la relación global-sectorial, cambios que devienen no solamente comprensibles sino también deseables. Así, podemos entender que habiendo cambiado el lugar de las mujeres en la sociedad, cambien igualmente las actitudes en relación con el nacimiento. A partir de aquí, las manifestaciones en favor de la libertad de interrumpir el embarazo no son percibidas como un problema de orden público sino como una reivindicación justa.

- Una operación de construcción de algoritmos operativos. Si bien la primera fase es una fase de análisis, se trata aquí de definir los operadores intelectuales que deberían permitir la acción y la transformación del sistema en el que se ha constatado una evolución. En efecto, es siempre a partir de la constatación que las cosas han cambiado que se va a definir una acción para acelerar (a veces frenar) este cambio. Estos algoritmos toman la forma de preceptos que definen a la vez la necesidad (la oportunidad) y las modalidades de la acción: «hay demasiados agricultores, es preciso disminuir el número de explotaciones»; «la apertura de las fronteras favorece el crecimiento económico»; «en una época de armamento nuclear, los batallones de infantería devienen inútiles»; «la disminución de las cargas de las empresas favorece el empleo»; «los gastos sociales son demasiado elevados». En cada caso podríamos definir el algoritmo inverso que haría referencia a otra imagen de la relación global/sectorial.

- Finalmente, una operación de integración de estos algoritmos en los valores que les darán la fuerza y la oportunidad necesarias. No es preciso hacerse una representación de los procesos de elaboración de un referente como un proceso racional o técnico. En realidad se trata de un proceso cultural que puede poner en cuestión los valores más fundamentalmes de los individuos, lo que explica a su vez la violencia que acompaña a menudo estas fases de cambio de la matriz de referencia de una política. Cuando un nuevo sistema de valores y de normas se impone de esta forma nos encontramos ante el signo de un cambio de referente global. 
En efecto, el referente de una política pública puede descomponerse en un referente global y en un referente sectorial.

1) El referente global es una representación general en torno a la cual se ordenan y se jerarquizan las diferentes representaciones sectoriales. Está integrado por un conjunto de valores fundamentales que constituyen las creencias de base de una sociedad y de una serie de normas que permiten elegir entre las conductas posibles. A este nivel, constituye la representación que una sociedad se hace de su relación con el mundo en un momento determinado. Contrariamente a lo que una definición excesivamente superficial podría hacernos pensar, el referente global no constituye una representación perfectamente coherente del mundo. En efecto, los valores que la componen son ellos mismos el seno de conflictos (por ejemplo, actualmente el lugar de lo social o de la función pública). El referente global no es objeto de consenso sino que baliza el campo intelectual en el seno del cual se producirán los conflictos sociales.

El conjunto de valores y de normas del referente global forma un sistema jerarquizado, lo que significa que en una determinada época ciertas normas tendrán prioridad sobre otras. Por ejemplo, los años cincuenta fueron testigos, en Francia, de la introducción de una nueva jerarquía de normas de la intervención pública; después del doble traumatismo de la derrota de 1940 y de la liberación las normas que privilegiaban el equilibrio y el mantenimiento de las relaciones sociales se identifican con el pasado y ceden el paso a las normas que valoran la apertura y la transformación de la sociedad: movilidad, cambio, modernización pasan a ser las nuevas expresiones que se imponen. A partir de este momento, el conjunto de las políticas públicas que estaban construidas en función de un referente de equilibrio se encontrarán en una situación delicada dada la transformación experimentada por el referente global. De ahí la sucesión de reformas políticas cuyo objeto es precisamente la adecuación del referente de las políticas sectoriales con el nuevo referente de modernidad: reforma hospitalaria, reforma de la política escolar, del urbanismo y de la vivienda, de la agricultura, de la cultura... Ningún sector escapa a la resituación en coherencia con los cambios experimentados.

Actualmente, en Francia, presenciamos un nuevo proceso de reajuste a partir de las normas derivadas de la crisis económica: limitación de los gastos públicos, modernización del Estado, reconocimiento de la empresa y de la primacía del mercado, integración europea... Este nuevo referente global se basa principalmente en la rearticulación de lo social y de lo económico (con la afirmación de una norma de limitación de los gastos sociales se introducen nuevos medios de intervención, como la renta mínima de inserción y la renovación de las empresas), en la redefinición de la frontera público-privada (con la pérdida 
de consideración del Estado como motor y la introducción de políticas económicas liberales) y en una nueva transacción entre el centro y la periferia con la descentralización de 1982.

2) El referente sectorial es una imagen del sector o de la profesión. En efecto, la configuración de un sector como la agricultura, los transportes o la energía depende estrechamente de la representación que nos hagamos del lugar que ocupan la agricultura, los transportes y la energía en la sociedad. Las fronteras de un sector son el objeto de conflictos permanentes de acuerdo con las controversias sobre la inscripción en la agenda política. Al igual que el referente global, el referente de un sector es una construcción social en el que la coherencia no es nunca perfecta. En el seno de un sector dado coexisten al mismo tiempo varias concepciones de la naturaleza y de la extensión de los límites sectoriales, siendo una de ellas en general la dominante, generalmente porque es la que más se adecúa a la jerarquía global de las normas que conforman el referente global. Es entonces esta representación la que se impone como imagen de referencia para la política pública correspondiente en la medida que genera los elementos de articulación entre global y sectorial.

El estudio de una política pública pasa, pues, necesariamente por preguntarse sobre cómo tiene lugar de forma permanente (no únicamente durante la fase de elaboración) la transacción entre referente global (lo que supone descubrir la estructura normativa) y un referente sectorial. El problema consiste pues en descubrir los actores que realizan esta operación de transacción y las posiciones de poder que implican: estos son los mediadores.

A partir de esta estructura, es posible comprender mejor el desarrollo de una política pública como la política agrícola francesa.

\section{EMERGENCIA Y DESARROLLO DE UNA POLITICA SECTORIAL}

Tal y como se desarrolla en Francia a principios de este siglo, la política agrícola se caracteriza por una voluntad política de presencia en el campo, como lo prueba la creación, en 1881, del Ministerio de Agricultura. Frente a las fuerzas conservadoras, la nueva República nacida después de la derrota de 1870 quiso demostrar de forma inmediata su interés por la gente campesina. La segunda característica de la política agrícola fue una voluntad, no tanto, como ocurre actualmente, de introducir cambios en la agricultura, sino de frenar su evolución, como muestra claramente la política de protección aduanera a la que el ministro Jules Méline unió su nombre. 


\section{Un referente de mantenimiento}

La cuestión es, pues, saber cuál era el sentido de aquella política que muchos observadores no han dudado en calificar de «arcaica». En realidad, estos observadores cometen un anacronismo, ya que juzgan la política agrícola de principios de siglo con los esquemas de pensamiento posteriores a la segunda guerra mundial, cuando las políticas públicas tienen «naturalmente» por función hacer evolucionar el sector en cuestión. Nada de qué ver, al contrario, con la época de Jules Méline: la política agrícola de la III República estaba perfectamente de acuerdo con la relación global-sectorial que existía por aquel entonces. ¿Cómo la podemos caracterizar?

A nivel global, para empezar, las exigencias de la sociedad francesa de la época con respecto a la agricultura correspondían a una exigencia de reproducción económica y a una función de estabilización política. El modelo de desarrollo adoptado por Francia en este período está fundado, contrariamente al ejemplo inglés, en la expansión internacional de los capitales bancarios más que en la industrialización del país. Entonces, la agricultura no era considerada como una salida industrial o una reserva de mano de obra. En aquel contexto, una política de mantenimiento de los equilibrios rurales se explica aún más fácilmente dado que, desde un punto de vista político, la espera con respecto al campesinado cumplía una función de estabilización del sistema de fuerzas en presencia. Traumatizada por el baño de sangre de la Comuna de París, la República temió el ascenso de las clases «peligrosas». Para controlar este riesgo, la alianza con el campesinado, que aparece entonces como una clase de apoyo, es un objetivo esencial. En estas condiciones, el objeto de la política agrícola es a la vez el mantenimiento de los equilibrios socio-económicos rurales y la socialización progresiva de las clases campesinas en el nuevo régimen que se presenta como el protector de la pequeña explotación y el distribuidor de las nuevas invenciones.

En definitiva, esta política agrícola muestra una perfecta adecuación con la relación global-sectorial de la agricultura a principios de siglo: expresa exactamente el lugar y el rol de la agricultura, o más aún del mundo rural, en el seno de la sociedad francesa de la época. De ahí que el referente de la política agrícola fuera en principio estructurado en torno a una norma de estabilidad que jerarquizaba la norma de la modernidad o adaptación, que si bien no estaba ausente sí era considerada secundaria. De acuerdo con esta matriz normativa, la política agrícola adoptó como objetivo prioritario mantener, en la medida que fuera posible, el máximo número de campesinos en el campo, incluso si el coste a pagar por ello fuera el de una menor modernización. 


\section{El desarrollo de un corporativismo agrícola}

Esta política agrícola ha sido la adoptada por Francia hasta 1940, si bien algunos cambios se dejan sentir con anterioridad. Pero con el traumatismo de la segunda guerra mundial todos los componentes del sistema se verán afectados: la relación global-sectorial característica de principios de siglo se desestabiliza de forma definitiva. En efecto, a partir de la liberación, la sociedad francesa abandona la búsqueda del equilibrio y el malthusianismo de antes de la guerra para adoptar la «opción» de la expansión y de la modernización. A ciencia cierta, habrá que introducir algunos matices en la medida que, como es bien sabido, el vuelco no se produce en un día. Pero la guerra, o más exactamente la derrota de 1940, y después la liberación por los ejércitos anglo-americanos en 1944, mostraron a los franceses que formaban parte de una verdadera nación industrial, dominadora de la fuerza mecánica. En estas condiciones, cabía esperar que el rol económico y social de la agricultura cambiase completamente: se convierte en un sector productivo integrado en la economía nacional, en realidad internacional, del que se espera que sea a la vez una salida para la industria y una reserva de mano de obra susceptible de alimentar la industrialización. Consecuencia lógica: la política agrícola, hasta entonces estructurada en torno al referente de equilibrio, se encuentra cada vez más en una situación delicada en relación con las políticas económicas de después de la guerra.

Todas estas transformaciones de la sociedad francesa, en efecto, no dejaron de tener sus efectos sobre la agricultura como tal, y los años cincuenta aparecen como un período intenso en abundantes iniciativas individuales o colectivas. El cambio afecta, de entrada, a las explotaciones agrícolas, o al menos a una parte cada vez más importante de aquéllas: el oficio de agricultor se transforma profundamente, el cultivador familiar dedicado al policultivo-cría poco intensiva, cede progresivamente su lugar al cultivador especializado en una producción y que intensifica sus métodos de cría o de cultivo. En otras palabras, el campesino se profesionaliza, lo que significa que cada vez se encuentra menos en un espacio territorial (comunidad de vecinos) y más en un espacio profesional o sectorial en el que las organizaciones agrícolas van a definir las nuevas reglas de excelencia y, por tanto, una nueva identidad campesina sobre la base no ya de la relación con el territorio sino de la competencia técnica.

¿Quiénes son estos «nuevos campesinos»? Se trata de jóvenes agricultores salidos de regiones con una fuerte tradición agrícola, como el oeste de Francia, que a menudo fueron formados por los movimientos de acción católica entonces en su apogeo. Convencidos del valor de la 
acción colectiva, se encuentran en el origen de una multitud de organizaciones que militan en favor de la modernización agrícola. Sobre todo, invierten en las organizaciones sindicales agrícolas empezando por las organizaciones de jóvenes (el Centro Nàcional de Jóvenes Agricultores, o CNJA) para acabar por tomar las riendas, a mitad de los años sesenta, de la FNSEA (Federación Nacional de los Sindicatos de Explotadores Agrícolas).

De esta forma, consiguen la transformación de estas organizaciones en un sindicalismo de profesión y, sobre todo, transformar completamente el discurso y las reivindicaciones del sindicalismo agrícola en relación con el Estado. Actualmente, el objetivo asignado al sindicalismo es el de promover la modernización de la agricultura, incluido el fomento del éxodo agrícola y la expansión de las explotaciones, lo que en el contexto de la época supone violar el tabú más profundamente anclado en las conciencias campesinas. Todas las condiciones de la relación global-sectorial son así modificadas, en parte bajo el efecto de las políticas del Estado mismo, de modo que al final de los años cincuenta el desfase entre el referente de la política agrícola (que continúa, a pesar de algunos retoques, dominada por la norma del mantenimiento) y la evolución de la relación global-sectorial pasa a ser verdaderamente gigantesca: ha llegado la hora de una nueva política.

\section{8: un cambio de referente}

La alternancia de 1958, con la llegada del general De Gaulle al poder, proporciona la oportunidad de introducir una nueva política. En efecto, los principios de la $\mathrm{V}$ República son marcados por manifestaciones de campesinos muy violentas que obligan al nuevo primer ministro a adoptar rápidamente una posición sobre un problema que de entrada él no consideraba verdaderamente prioritario. ¿Cómo percibe el problema agrícola Michel Debré? Se podría afirmar que tenía una idea fija: conseguir la modernización de la economía francesa. En este contexto, la agricultura aparece, ante todo, como un obstáculo al crecimiento. El Gobierno no tiene pues idea, para decirlo de forma clara, sobre lo que debería ser una política agrícola, pero en cambio sabe que dicha política deberá estar de acuerdo con los objetivos de modernización asignados al conjunto de la economía.

Es en este momento que se produce el «descubrimiento» por el poder de la tesis del CNJA. Esta es una organización, cuya legitimidad en el medio campesino es indiscutible, que propone una visión de la agricultura exactamente conforme a la que el primer ministro necesita: prioridad a la modernización y a la extensión de las haciendas, fomento de la salida de los agricultores «sobrantes», cuestiones que se inte- 
gran perfectamente dentro de las perspectivas generales definidas por el Gobierno. No sorprende pues que, en estas condiciones, se alcancen rápidamente acuerdos entre el poder y los representantes de la nueva generación campesina, acuerdos que serán sancionados con el reconocimiento al CNJA de una representatividad igual a la del FNSEA.

El poder designa, por tanto, su interlocutor privilegiado en el medio, confiriéndole al mismo tiempo un plus de legitimidad considerable. Desde este momento, las cosas pueden avanzar rápidamente. Durante la primavera de 1960 , una serie de reuniones confidenciales reúnen a los representantes del poder, por un lado, y al estado mayor del CNJA (en particular Michel Debatisse, quien pasa a ser después presidente del FNSEA). De estas reuniones surgió un proyecto de ley, adoptado por el Parlamento durante el verano, que modifica completamente las bases de la política agrícola francesa. En primer lugar, la nueva ley afirma que el objeto de la política agrícola consiste en fomentar el levantamiento de explotaciones agrícolas viables (lo que significa que todas no lo son) definidas como aquellas que producen una renta correcta para dos personas. En segundo lugar, la ley establece una serie de mecanismos destinados a facilitar la transformación de las estructuras de las explotaciones agrícolas, principalmente en materia de fomento de la extensión de las haciendas. Estas medidas fueron completadas más tarde con la introducción de un sistema que incentivaba el abandono de las tierras por parte de los agricultores de edad avanzada con el propósito que sus tierras pudieran servir para hacer mayores otras propiedades.

Se trata de un vuelco completo del referente de la política agrícola. En lo sucesivo, la norma de la adaptación pasa a ser la dominante y va a jerarquizar la norma de la estabilidad. En el discurso de la política agrícola, las llamadas a la movilidad social pasan a ser más importantes que los valores de equilibrio. Es preciso poner de relieve el rol estratégico del CNJA en esta operación de readaptación de la jerarquía de las normas de la política agrícola a las nuevas exigencias de la relación global-sectorial. Su rol, en efecto, se desarrolló a un triple nivel.

- Para empezar, sus representantes supieron descodificar e interpretar la evolución de la relación global-sectorial con el objeto de hacerla inteligible a las masas campesinas. Como hemos visto más arriba, no hay que ver en esta operación de descodificación un simple proceso de elaboración intelectual sino una ideología en práctica, esto es, integrada en los actos y lọs conflictos que se estaban produciendo en el mundo rural en aquella época.

- Además, el CNJA contribuyó a reformular en términos de acción este análisis de la nueva situación de la agricultura, per- 
mitiendo de esta forma al campesinado (o al menos a una parte de éste, en cualquier caso) hace"se cargo de su propia modernización.

- Por último, el estado mayor del CNJA consiguió que el poder aceptara las principales medidas que iban a marcar la acción del Estado en el campo durante los años siguientes.

En otras palabras, el CNJA (entendido aquí como la parte más visible de un movimiento social mucho más amplio) ejerció un rol muy importante de mediación, dado que no se contentó con proponer una nueva jerarquía normativa, sino que de alguna forma tomó el lugar de la Administración en lo que concierne a la definición de los nuevos procedimientos de la política agrícola. Al mismo tiempo, el CNJA en cierta medida integró un rol de mediador sectorial dentro de un proceso más amplio de acceso de una nueva clase campesina a la dirección del sector agrícola, ambos procesos coadyuvándose mutuamente. Por esta razón, estos hechos no iban a dejar de tener efecto sobre el mismo sistema de intervención.

\section{La recomposición de las relaciones Estado-profesión}

Sabemos que la política agrícola había sido elaborada a partir de los contactos directos entre los servicios del primer ministro y los dirigentes del CNJA, dejando de lado al Ministerio de Agricultura. Así, cuando el nuevo ministro de Agricultura, E. Pisani, asume sus funciones en 1961 con el propósito de dirigir directamente las negociaciones sobre la implementación de la política agrícola común y la puesta en práctica de la nueva política de modernización, su primera impresión es que no dispone de los mecanismos adecuados para su política. Se encuentra ante un verdadero vacío administrativo en el que la profesión va a meterse, mostrando al Gobierno todas las ventajas que obtendría si le confiara la ejecución de la política de modernización de la agricultura.

Dado que se trataba de poner en práctica una política de incentivación de las salidas de la agricultura, la profesión podía efectivamente aparecer como mejor situada que la Administración, inicialmente encargada de la operación. En realidad, ambos tenían interés en introducir fórmulas de «cogestión». Para el Gobierno, éstas suponían confiar a una profesión la responsabilidad de su propia «reestructuración» y, por tanto, la asunción de todos los riesgos debidos al descontento que esta política iba a provocar. Para los sindicatos, en cambio, la asunción de esta política, con todo su cortejo de subvenciones y de ventajas diversas, constituía evidentemente una ocasión excelente de forta- 
lecer su dominio sobre el medio y en consecuencia su leadership sectorial.

La política de modernización es, pues, aplicada a través de un dispositivo original que deja claramente de lado al Ministerio de Agricultura, sobre todo a nivel departamental. Así, el círculo se cierra: nueva relación global-sectorial, nueva política, nuevo sistema de intervención basado en la cogestión y una nueva estructura de poder en el sector. Es a partir de este momento que durante unos quince años se pone en marcha un sistema de cogestión corporativista de la política agricola sobre la base de una colaboración extremadamente estrecha entre el poder político y las organizaciones profesionales (KEELER, 1987). El símbolo de esta cogestión es la conferencia anual que reúne cada año las principales organizaciones agrícolas y a los representantes del poder con el propósito de debatir las orientaciones de la política agrícola (COULOMB, 1990).

No es hasta 1981 que este sistema de relación Estado-profesión se iba a quebrantar.

\section{1: la mediación inacabada}

El período de principios de los años sesenta se corresponde con una especie de caso paradigmático de alternancia con éxito: un nuevo. Gobierno se encuentra con un actor profesional; juntos, proceden a un cambio de referente, lo que facilita al mismo tiempo el acceso al poder, en el seno del sector, de los representantes de este grupo. 1981 constituye, por el contrario, el fracaso de un intento de cambiar el referente de la política agrícola, lo que no impide que las cosas cambien, pero no precisamente en el sentido previsto inicialmente. Cuando la nueva ministra de Agricultura, Edith Cresson, toma posesión de su cargo, su objetivo era aplicar estrictamente el proyecto agrícola del PS. Este programa se proponía introducir una mayor justicia social en la agricultura gracias a un sistema de precios diferenciados, frenar el éxodo rural que es percibido como una causa de desempleo y cuestionar el monopolio de la representación del FNSEA, heredado del período anterior.

Un programa de estas características supone el trastocamiento de la jerarquía normativa del referente de la política agrícola, en la medida que la norma de adaptación es jerarquizada por una norma de solidaridad. Para ponerla en práctica, la ministra intentará apoyarse en el sindicalismo agrícola de izquierdas, reconociendo de entrada la representatividad del conjunto de sindicatos minoritarios excluidos hasta entonces de la práctica de la cogestión. El problema radica en que la situación de 1981 difiere de la de 1960. A nivel de sector, el sindicalis- 
mo de izquierda se encuentra lejos de tener la influencia de la que se beneficiaron en su época los portavoces del CNJA. El discurso de los «Paysan-Travailleurs», impregnado de una perspectiva de lucha de clases, está desfasado respecto a la experiencia cotidiana de la mayoría de los agricultores que viven más bien como artesanos independientes. A nivel global, se presenta el problema de la adecuación de la política de Edith Cresson con los objetivos macroeconómicos del Gobierno. En la medida que prevaleciese lo que podríamos denominar un referente de solidaridad a nivel global, podría admitirse la idea de reforzar la justicia social y de frenar el éxodo agrícola. Pero a partir de 1983 la norma de solidaridad cede su lugar a la norma de la competitividad: tomando nota del carácter inevitable de los condicionantes exteriores, el Gobierno se resuelve a adoptar su voluntad de reforma al ritmo de la máquina económica. Es el triunfo del referente de mercado. El referente de la política agrícola se encuentra de nuevo en una situación de desajuste en relación con la RGS y por ello pierde legitimidad, como lo demuestra la sustitución de Edith Cresson por Michel Rocard con la misión de poner fin a los conflictos. La operación de mediación babia fracasado.

Sucede sin embargo que, si bien en un sentido distinto al que previeron los responsables socialistas, el lugar de la agricultura en la sociedad cambió a partir de 1960 y los responsables profesionales comenzaron a encontrarse asimismo en una situación de desajuste. Cuando fueron votadas las leyes de orientación de 1960 y 1962, el Mercado Común solamente estaba empezando y la apertura de fronteras constituía únicamente una posibilidad lejana. Era posible negociar, entre el Estado y la profesión, un compromiso, permitiendo, gracias a la protección del Estado proceder al ajuste de las transformaciones agrícolas de forma que no se desestabilizara el sistema manteniendo la dirección del nivel dominante. Pero a partir de 1980 el sistema ya no funciona tan bien. De entrada, genera excedentes cuyo coste deviene insoportable. Además, cada vez está más en contradicción con la necesidad de competir con el exterior: claramente abierta a Europa, Francia debe además alinear su política económica con la de sus socios. Es por ello que cuando la Comisión de Bruselas propone la introducción de un sistema de cuotas para controlar la producción de excedentes, la profesión agrícola no tiene otra opción que la resignación. Esta vez la operación de mediación se produce al margen de la profesión agrícola. Si bien ésta había conseguido, en 1960, hacer surgir a un mediador de entre sus rangos que podía negociar de igual a igual con el Gobierno, ahora se veía obligada a aceptar pasivamente las soluciones impuestas por un mediador de otro tipo, cuyo poder crecía de forma vertiginosa: la Comisión de las comunidades europeas.

La comparación de los dos períodos pone, pues, de relieve la relación central que existe entre el contenido del referente sectorial, la 
naturaleza del sector en cuestión y las relaciones de dirección en el mismo. En 1981, el Poder intentó cambiar de referente sin cambiar las fronteras del sector (que se identificaba tradicionalmente con la franja agro-alimentaria) y sin poder cuestionar la dirección de las organizaciones dominantes. Su margen de maniobra era, pues, muy limitado.

\section{LA POLITICA AGRICOLA FRANCESA ANTE EL CAMBIO: LA CRISIS DE LA APROXIMACION SECTORIAL}

Desde hace algunos años asistimos, pues, a una verdadera crisis conceptual de la política agrícola en la medida que los mecanismos esenciales que habían sido puestos en funcionamiento para gestionar la modernización de la agricultura muestran sus limitaciones, dada la nueva situación económica internacional. A partir de aquí, y para circunscribirnos más específicamente al caso francés, podemos preguntarnos si estos problemas agrícolas no tienen relación con la crisis de un modelo de Administración pública típicamente francés, que consiste en promover el desarrollo a través de líneas relativamente estrechas, bajo la dirección del Estado y gracias a la cooperación de élites profesionales que obtienen el monopolio de la representación (sobre este tema cf. SCHMITTER, 1979).

\section{Una lógica lineal (2)}

En perspectiva, la modernización de la agricultura francesa, que ha dado lugar a un incremento considerable de productividad, y asimismo a un cierto desarraigo cultural de los campesinos, presenta características que explican directamente los problemas actuales. En efecto, contrariamente a una cierta retórica que prosperó en aquella época, los cambios de los años sesenta no transformaron a los campesinos franceses en empresarios (si exceptuamos la gran agricultura del norte de Francia). El «joven agricultor moderno y dinámico que dirige, con su esposa, una explotación lechera de unas cincuenta vacas en el Oeste de Francia», que constituye de alguna forma el tipo ideal y el modelo de esta «revolución silenciosa», es fundamentalmente un ingeniero: su competencia proviene de la producción. Los aspectos comerciales, en cambio, son ampliamente ignorados, transferidos al aparato agro-alimentario, que se encarga de la transformación y de las ventas en el mercado. Para resumir, en la explotación agrícola modernizada, la función comercial es externalizada, excluida del referente profesional como lo

(2) Nota del traductor: «filière» en francés. 
demuestra la ausencia de líneas de formación en este campo. Así pues, la política agrícola francesa ha producido una generación de agricultores competentes en el plano técnico pero incapaces de gestionar las implicaciones comerciales de su actividad y que no tiene otro recurso, cuando las cosas van mal que recurrir al Estado: la política agricola ba producido una agricultura administrada por el Estado. Nos encontramos en el centro de lo que hemos denominado más arriba el referente modernizador: el Estado, apoyándose en una corporación agrícola que dispone de un monopolio de representación, ha llevado a cabo una política voluntarista de modernización del aparato productivo con resultados espectaculares en el plano técnico. Pero esta política, que se basa en un sistema de corporativismo sectorial en el que la Administración y los responsables de los sectores colaboran con la definición de la puesta en práctica de la política, legitimándose así mutuamente, sólo funciona en circuito cerrado, esto es, en la medida que los diferentes actores consiguen controlar suficientemente los efectos del mercado.

Además, la incapacidad de los mecanismos comunitarios para controlar las crisis recurrentes de sobreproducción a pesar de los notables esfuerzos financieros es cada día más evidente. La introducción de sistemas como los de las cuotas lecheras y el enfrentamiento cada vez más severo con los Estados Unidos en el marco del GATT, muestran los límites de la lógica lineal de la Administración. Para utilizar la expresión de Clude Servolin, los Gobiernos europeos deben hacer frente a un fallo del «Estado providencia agrícola» y que consistía en intercambiar modernización técnica por un cierto derecho a producir independientemente de las fluctuaciones del mercado (SERvOLIN, 1989).

Este modo de promover el desarrollo económico-social, típico del modelo francés, es actualmente puesto en duda. Podemos constatar, en particular, una distorsión creciente entre la lógica de reproducción de la rama agrícola que va en el sentido de una agricultura especializada cada vez más indiferente a su entorno inmediato, de una parte, y las exigencias de desarrollo local, de otra parte. Los problemas de la desertización del campo y, más recientemente, los perjuicios causados al medio como consecuencia de las prácticas agrarias fuertemente artificiales, son las manifestaciones más claras de esta ruptura histórica entre la agricultura (como sector) y el entorno rural (como espacio social). En realidad, el conjunto del mundo rural se transforma y pone en cuestión la imagen de la agricultura que se encuentra en el núcleo del referente de la política agrícola. 


\section{La transformación de las sociedades rurales francesas}

En efecto, la evolución de la agricultura y del mundo rural en Europa coduce al conjunto de observadores y de decisores en materia de políticas rurales a modificar sus percepciones de los problemas rurales. Los esquemas forjados a lo largo del período de modernización triunfal de los años cincuenta y sesenta no permiten ya aportar una respuesta coherente a las dificultades de la agricultura francesa y, de forma más amplia, a la cuestión del desarrollo del empleo en el medio rural. Estas transformaciones del mundo rural se manifiestan a un triple nivel (Cf. Bodiguel, 1986; HouÉE, 1989; KAYSER, 1990):

- Una cierta convergencia en los modos de vida. Durante mucho tiempo, el campo se ha asociado a la idea de un modo de vida arcaico. En la actualidad, todos los estudios lo demuestran, el modo de vida rural es cada vez menos distinto del urbano. Subsisten sin embargo algunas divergencias todavía: el hábitat agrícola en sentido estricto está subequipado; el consumo cultural, de sanidad, de ocio no son aún iguales. Globalmente, observamos el acercamiento claro de los modos de vida, probablemente más fuerte en el entorno rural no agricultor, pero que acaba por alcanzar a todos los estratos sociales. Vemos por ello cómo se expresan en el medio rural las mismas exigencias en términos de acceso a la salud, a la cultura o a las vacaciones que en el medio urbano, y cómo las diferencias son cada vez más percibidas como una desigualdad que debería desaparecer.

- Nuevas evoluciones demográficas. Se trata de la tendencia, que han señalado varios observadores, a la inversión de los flujos demográficos. Si bien una parte del «mundo rural profundo» prosigue con su declive anunciado, descubrimos cómo ciertas zonas, a pesar de ser claramente rurales conocen una renovación demográfica, lo que ha llevado a algunos observadores a evocar un «renacimiento rural» sobre la base de la inversión de las corrientes migratorias. En el período 1975-1982 se produce el vaivén que rompe con una evolución secular. Mientras que entre 1954 y 1962 los pueblos rurales tuvieron un déficit de un 1 por 100 por año, en sentido contrario se produce una ganancia a su favor del mismo orden a partir de 1975 . Se puede discutir la amplitud o la perennidad del fenómeno si bien parece globalmente confirmado por el último censo. Hay que tener en cuenta, sin embargo, que la inversión tal y como se refleja en las medias, no afecta de la misma forma a todas las zonas rurales, si bien, globalmente, la población rural aumenta en un 6,2 por 100 entre 1975 y 1982. 
Todo ocurre como si la inversión demográfica acentuara las diferencias, las disparidades entre un medio rural en declive y un medio rural que vuelve a nacer transformándose al mismo tiempo. Son estas transformaciones las que van a modificar sensiblemente las reglas del juego en el campo.

- La agricultura minoritaria en el campo. Estas transformaciones, en realidad, conciernen a la misma estructura del medio rural, con una disminución constante del peso de los agricultores, y de forma más general de los estratos sociales tradicionales, y una diversificación creciente de la población rural gracias al aumento de la proporción de oficios no agrícolas. En el siglo pasado, el mundo rural estaba principalmente constituido por agricultores y por las categorías sociales que gravitaban alrededor de la agricultura. Son estos grupos los que se vieron principalmente afectados por el éxodo. En sentido contrario, la inversión demográfica de estos últimos años es protagonizada por categorías sociales ajenas a la agricultura, dado que los agricultores no representan en la actualidad más que una cuarta parte del medio ruràl. Esto significa que si bien los campesinos continúan siendo una cateogría social importante, es realmente imposible asimilar, como lo hacíamos más o menos implícitamente hasta ahora, agricultura y medio rural.

A partir de estos datos, se puede afirmar que el medio rural está todavía ahí, pero que se ba transformado de tal forma que en realidad no se trata ya de la misma realidad social. Una evolución de este tipo tiene consecuencias importantes, en la medida que implica que la lógica del sector no está ya en condiciones de explicar por sí misma la evolucion del campo en la actualidad: ya no se puede asimilar desarrollo rural y desarrollo de la agricultura de producción. Ello implica, pues, una reformulación de los esquemas de análisis propios de los años de la modernización que, a partir de la constatación del declive demográfico, privilegiaron el reforzamiento técnico-económico (aunque no en número de empleos creados) de la rama agrícola.

En realidad es la percepción del espacio rural y de su rol en la sociedad francesa lo que debe cambiar, puesto que el espacio rural tiene hoy asignadas cuatro funciones principales:

- una función de producción agrícola que se corresponde con el rol tradicional pero que es objeto de una transformación profunda en la medida que la separación entre la línea de producción y el espacio rural propiamente dicho se ha ampliado de forma importante;

- una función de ocio que consiste en acoger y entretener tanto a la población rural como a la urbana; 
- una función residencial que genera una actividad dinámica de construcción y de mejora del hábitat;

- por último, una función que tiene que ver con el entorno y con la necesidad de preservar los equilibrios naturales, que todavía no han sido objeto de una verdadera actividad económica.

Estas mutaciones del mundo rural ponen de relieve la crisis del referente profesional en la agricultura a la vez que abren nuevas perspectivas de transformación del oficio de agricultor.

\section{Tres rupturas}

«El problema campesino actual», ha escrito Bertrand HERVIEU, «es el reflejo de la dificultad encontrada para reformular un proyecto político para los agricultores y la agricultura. Las manifestaciones del verano de 1990, mostrando una clara desesperanza, incluso a través de las formas más absurdas de protesta, pusieron de relieve la profundidad de la crisis del campo en Francia». En efecto, esta crisis va mucho más allá de la tradicional agitación que anima al campo de forma recurrente. Lo que se está cuestionando hoy es, a la vez, una cierta concepción del oficio de agricultor, un cierto tipo de dirección profesional en el seno del sector y una determinada manera de tratar políticamente los problemas agrícolas. Esta crisis del oficio de agricultor se manifiesta, según Bertrand HERvieu, a través de tres rupturas fundamentales (Hervieu, 1990):

- Una ruptura en la relación agricultura/alimentación. «Por primera vez en la historia, la actividad agrícola deja de estar ligada a la función de alimentación que le había sido asignada. Los productores de cereales, por ejemplo, son percibidos más como productores de materias primas, esto es de moléculas, para las industrias de síntesis.» Ello significa que los consumidores, que jamás habían dedicado una parte tan pequeña de su renta a la alimentación, ignoran cada vez más la constitución de su alimentación: la alimentación corriente pasa a ser una abstracción, diferenciada de su origen.

- La segunda ruptura concierne las relaciones entre agricultura y naturaleza, que se manifiesta por una artificialización creciente de los métodos de cultivo y ganadería. Esta evolución, independientemente de su impacto ahora bien conocido sobre el medio, se traduce en una profunda transformación de las relaciones entre el campesino y su utillaje de trabajo (la tierra, el animal), que pasa a ser un factor de producción cada vez más abstracto. 
- La tercera ruptura puesta de relieve por Bertrand HERvieU tiene que ver con el binomio agricultura/familia: «el modelo de explotación familiar de dos "UTH" (Unidad Trabajo Hombre), base de la agricultura moderna, se desmorona» dado que hay una proporción creciente de agricultores que trabajan solos, ya sea porque viven solos o porque su consorte trabaja fuera de casa.

Estas tres rupturas llevan a muchos agricultores a preguntarse sobre el sentido de su trabajo, en la medida que un buen número de valores considerados inmutables (el campesino, guardian de la vida...) son cuestionados. En este sentido, la polémica sobre la responsabilidad de las formas modernas de agricultura en el desarrollo de la contaminación nos revela claramente la crisis de la identidad profesional campesina. De otra parte, sin embargo, la aceptación de la agricultura de producción como modelo por el conjunto de los actores económicos del campo es su causa.

\section{Crisis de liderazgo}

La crisis no se da únicamente en relación con una cierta concepción del oficio de agricultor concebido exclusivamente en torno a la función de producción, sino también entre la relación de liderazgo que se había instaurado entre la agricultura productiva especializada y las otras categorías sociales en el campo, esto es, los fundamentos mismos del corporativismo agrícola. En efecto, hemos visto más arriba, como una de las principales consecuencias de las transformaciones de la agricultura francesa en los años que siguieron a la segunda guerra mundial fue la emergencia de un modelo profesional que rompía con la imagen tradicional del campesino. La identificación de los campesinos se haría en lo sucesivo a través de una referencia profesional, la pertenencia a la categoría social de los agricultores, dependiente a su vez de la capacidad de adecuarse a las reglas de pertenencia a la profesión. Se distingue, pues, entre los «profesionales» y los «otros», si bien este mecanismo de inclusión o exclusión no es perfecto y los criterios de pertenencia a la profesión no son completamente claros. En realidad, como demuestran los trabajos de Jacques RémY, la definición de los criterios de pertenencia es el centro de una lucha permanente por el control de la identidad profesional (RÉmY, 1987).

¿En qué se basan estos criterios? Esencialmente en la capacidad del agricultor de obtener un nivel técnico de explotación lo más elevado posible. Es la hora del campesino-ingeniero y es sobre la base de este modelo que se organiza el liderazgo de la agricultura especializa$\mathrm{da}$, no únicamente de la rama agtícola, sino de todo el conjunto del 
medio rural, de acuerdo con una combinación precisa de criterios de exclusión y de inclusión. Serán pues excluidos —al menos simbólicamente- en principio los de edad más avanzada, después los excesivamente pequeños y por último los que no ejercen su actividad a tiempo completo de acuerdo con un rehacer continuo de las normas de entrada en la profesión. Al mismo tiempo, las puertas no son nunca completamente cerradas. El problema, en efecto, consiste en validar la pretensión de la agricultura profesional de representar los intereses del conjunto de la agricultura y, aún, del conjunto del mundo rural.

Este sutil mecanismo deja de funcionar como consecuencia del efecto de las transformaciones indicadas más arriba:

- La especificidad del campesinado y del mundo rural es cada vez menos evidente, cuando era una de las condiciones esenciales de la unidad campesina.

- El mundo rural es cada vez menos agrícola. Aún peor, los agricultores especializados se encuentran en una situación más y más desfasada en relación con la evolución actual del mundo rural.

- Por último, el modelo profesional en sí mismo está en crisis a raíz de los cambios de políticas de apoyo a la agricultura. De ahí que la agricultura especializada sea menos atractiva para los que quieren instalarse ex novo.

Es en el contexto de estas nuevas funciones que hay que analizar las perspectivas de reforma de la política agrícola común. En efecto, si bien las nuevas propuestas de la Comisión tienen en cuenta las limitaciones, en términos de creación de empleo rural, del modelo de desarrollo por líneas de producción, no alcanzan necesariamente a cuestionar los modos de razonar que implican.

\section{La reforma de la política comunitaria}

Ciertamente, es todavía demasiado pronto para saber qué medidas precisas pueden derivarse concretamente del informe McSharry. Es evidente que determina una inflexión espectacular de la percepción del problema agrícola a nivel de las instancias europeas. Lo podríamos resumir en base a las dos siguientes ideas: reconocer la lógica del mercado y luchar contra la desertización.

La primera idea parte de constatar que la política agrícola común se encuentra en un atolladero: el coste de mantener los mercados crece (se ha multiplicado por casi tres entre 1980 y 1991, pasando de 11,3 billones de ecus a 32 billones). Al mismo tiempo, los stocks de leche, 
de cereales o de carne vacuna se incrementan de nuevo. Además es preciso constatar que, de forma paralela, la renta agrícola sólo aumenta en proporciones muy modestas. Por último, para completar este cuadro, la degradación del entorno se acelera de forma paralela a la desertización de vastas zonas rurales...

Ante la constatación de un sistema que se ha hecho «perverso», el informe propone distinguir entre los objetivos económicos y los objetivos sociales de la PAC. Por un lado, se quiere dejar hacer al mercado disminuyendo los apoyos a la agricultura económicamente viable, lo que permitiría a la vez reducir el peso financiero de la PAC y adecuarse a las exigencias formuladas por los demás socios del GATT. Por otro lado, se sugiere introducir un sistema de «solidaridad financiera» en beneficio de los demás agricultores, con el propósito de frenar su abandono en nombre de la protección del entorno y del rechazo de la desertización.

El problema es que la única vía que parece guardarse Bruselas para incentivar las funciones no productivas de la agricultura es la introducción de una política de carácter social, lo que viene a excluir las nuevas funciones de la explotación agrícola en el campo económico. Ciertamente, no pretendemos aquí que no se tome ninguna medida social a favor del medio rural, pero este tipo de raciocinio, en realidad, funciona como una verdadera trampa, dado que bajo la pretensión de reconocer nuevas actividades al agricultor se encierra a una buena parte de los campesinos en un estatuto de categoría socialmente asistida.

El único medio de salir de esta trampa consiste en reconocer e incentivar las nuevas calificaciones profesionales rurales que, situándose al margen de la rama de la agricultura de producción, sean conformes a la norma dominante del mercado. Esta idea podría dar lugar a la noción de agricultura de servicios para designar la actividad que ejercen los agentes económicos del medio rural al margen de las funciones estrictas de producción alimentaria. Pero un paso como este supone, evidentemente, reconsiderar de veras el enfoque sectorial de los problemas rurales...

\section{El medio rural como espacio empresarial}

Nos encontramos con que, desde hace una quincena de años, se multiplican en el campo nuevas formas de combinar actividades que se diferencian radicalmente del modelo dominante. En algunos casos, estas prácticas, que llamaremos explotación rural, por oposición a la explotación agrícola especializada (MULLER, GERBAUX, FAURE, 1989), consisten en ampliar el papel del campesino más allá de la función de producción propiamente dicha, transformando el producto para ofrecerlo 
directamente al consumidor final. En otros casos se utiliza la explotación como soporte de actividades turísticas (acogida en una granja). Otras veces aún se combina una actividad de tipo agrícola con una de carácter artesanal rural o una actividad de venta de servicios. Desde la perspectiva del referente dominante, estas tentativas son analizadas en términos de diversificación, lo que implica confinarlas a alguna forma de marginalidad: de un lado, los «verdaderos» profesionales que son objeto de la política agrícola y, del otro, el universo más o menos estructurado de las pluriactividades que ponen a flote las políticas de acompañamiento de carácter social.

Se puede argumentar, en sentido inverso, que estas experiencias individuales o microcolectivas llevan el germen de verdaderos sistemas profesionales con su propia coherencia y susceptibles de poner en cuestión los análisis excesivamente lineales sobre el declive del campesinado. El problema reside en que, contrariamente a la norma dominante, el oficio de explotador rural no se estructura de acuerdo con la función productiva sino por la función comercial, que permite así definir la lógica profesional de esta nueva calificación campesina: en la medida en que los aspectos comerciales son externalizados dentro del modelo de la agricultura de producción, se puede afirmar que una explotación rural funciona primero según una lógica comercial.

Consecuencia: el explotador rural no se define ya como un agricultor, sino como un empresario rural, dado que en lo sucesivo su oficio consiste en concebir, producir y vender un conjunto de bienes y servicios rurales en función de la demanda. El concepto de explotación rural da lugar a una agricultura de servicios sobre la base de un entramado de empresas que se sitúan claramente dentro de una lógica de mercado. Se trata de una triple ruptura con la política agrícola actual:

- al integrar ls dimensión del mercado y al asociar diversas actividades rurales, el explotador toma distancias en relación con la lógica sectorial centrada en la estricta expertise en la producción agrícola. Cuestiona por tanto el modelo profesional en el que se basa la política agrícola;

- al dominar (aunque sea de forma relativa) las funciones más importantes (transformación, venta...) el explotador rural se desentiende de la lógica de administración por ramas (la cuestión del mantemiento de los precios deja de interesarle);

- por último, la explotación rural se encuentra en relación directa con el desarrollo local; a diferencia de la agricultura de producción, no se desarrolla en un espacio sectorial (de línea productiva) sino en un espacio de localidad. El emprendedor de servicios puede convertirse en un agente de desarrollo local, puesto que su explotación sólo funciona en base al entramado de conexiones con su entorno económico y social próximo. 
Podemos comprender mejor, en estas condiciones, las dificultades para introducir una política del espacio rural en Francia. En la medida que el desarrollo rural sigue asimilado al de la rama agro-industrial, ninguna apertura es posible en relación con la lógica administrativa y sectorial que excluye del campo profesional todos aquellos que no alcanzan las normas de excelencia. Todo ocurre como si el sistema de colegitimación entre el Ministerio de Agricultura y la corporación agrícola fuera incapaz de superar la referencia profesional sobre la que se fundamenta todo el sistema: el modelo de agricultor especializado e intensivo, en la que se fundamenta la forma de pensar tanto de los funcionarios como de los dirigentes agrícolas, parece impedir todo tipo de evolución.

\section{¿Políticas sectoriales o politicas locales?}

En definitiva, la cuestión clave es la de la finalidad de las políticas públicas en relación con la agricultura y el mundo rural. Ciertamente, parece claro que el fomento al desarrollo de una forma de agricultura de servicios tendrá muchas dificultades para situarse en el marco de una política sectorial de carácter nacional como la política agrícola actual.

La política agrícola que se ha ido implementando a lo largo de los años cincuenta y sesenta es adecuada para gestionar líneas de producción, dado que el espacio de reproducción de la agricultura ya no es el territorio sino la rãma agro-alimentaria. ¿Qué es, sin embargo, lo que importa al explotador agrícola en la actualidad? Todo lo relacionado con su proceso de producción: el precio del petróleo y de todos los productos de los que tiene necesidad (los alimentos para el ganado, el engorde...) y lo que se decide en Bruselas. En cambio, lo que ocurre en su entorno inmediato no tiene tanta importancia. Más específicamente, la degradación de su entorno social (desertización) podrá suponerle problemas a nivel de su vida cotidiana, pero tendrá un impacto muy reducido sobre el funcionamiento técnico-económico de la explotación. Existe, pues, crisis de desarrollo local puesto que los centros de decisión económicos ya no se encuentran en su región, sino a nivel europeo o mundial. El modelo técnico-agrícola ha producido una agricultura «desligada del suelo» por lo que respecta a su entorno inmediato, lo que significa que no tiene que producirse necesariamente una relación estrecha entre la reproducción de la rama agrícola y la reproducción de las economía locales, que se encuentran, por tanto desarticuladas.

La agricultura de servicios está, al contrario y por definición, muy relacionada con el desarrollo local. En efecto, a diferencia de la agri- 
cultura de producción, no se desarrolla en un espacio sectorial (de rama o línea de producción) sino en un espacio de localidad. De ahí que su lógica de funcionamiento sea diferente y que el problema de su articulación con el espacio rural se plantee de otra forma: el empresario de servicios puede convertirse en un agente de desarrollo local, ya que su explotación sólo funciona a través de establecer múltiples ligámenes con su entorno económico y social próximo.

Vemos así por qué la agricultura de servicios, mucho más que la agricultura de producción, es susceptible de ser objeto de políticas locales. No deja de sorprender que un alcalde rural no tenga demasiados asuntos que discutir con un explotador rural especializado, dado que el municipio no constituye un centro de decisión pertinente para este último (al menos en tanto que profesional). La agricultura de producción se encuentra al margen de las intervenciones de los políticos locales en materia de desarrollo económico local (FAURE, 1989). La agricultura de servicios, al contrario, por razón de su carácter localizado y de su dimensión comercial, se integra fácilmente en una perspectiva de dinamización del municipio o del país.

La cuestión radica, pues, en desarrollar, paralelamente a las políticas agrícolas de línea de producción, una verdadera política rural que consista, por ejemplo, en poner en marcha acciones conjuntas con los políticos locales preocupados por el desarrollo económico de su localidad. Pero esta transformación (aunque sea parcial) del enfoque sectorial de las políticas públicas, ¿está verdaderamente en la perspectiva de la Administración actual? En cualquier caso, ello implica, al cuestionar el paradigma de la sectorialidad, un cambio profundo de referente de las políticas rurales francesas.

\section{LA POLITICA AGRICOLA Y LA CRISIS DEL MODELO FRANCES DE ADMINISTRACION PUBLICA}

Estas dificultades de la política agrícola explican, por último, que nos preguntemos sobre el conjunto de los modos de operar de la Administración francesa. ¿Cuál era el fundamento del modelo políticoadministrativo francés de los años de después de la guerra antes de hacerse sentir sus limitaciones con la crisis de los años sesenta? Cabe distinguir tres elementos fundamentales:

- Un modo de distribución del expertise técnico adecuado que se concentraba en las manos de los grans corps del Estado y que permitía a estos últimos de responsabilizarse sector por sector de la modernización del país. En los campos de la energía, de la aeronáutica, de la agricultura o de la planificación del terri- 
torio observamos la impronta de este enfoque a la vez técnico, centralizado y sectorial que marcan el punto álgido de la Administración francesa de los años cincuenta y sesenta.

- Una cierta representación de la dualidad público-privado que confería al Estado un rol motor en la gestión del desarrollo económico y social. Este segundo aspecto, obviamente muy relacionado con el primero, condujo a poner sistemáticamente por delante un «interés general» superior a los intereses privados que incarnaba la alta función pública.

- Por último, un modo específico de articulación de los intereses sociales basado en la fragmentación de los sistemas de representación, cada categoría social manteniendo relaciones privilegiadas, cuando no exclusivas, con un segmento de la Administración, desembocando todo ello en una forma específica de corporativismo a la francesa que podríamos calificar de corporativismo sectorial.

Estos tres elementos estaban asimismo integrados en una representación global de la sociedad y del rol del Estado fundado en la idea de la modernización. Este referente modernizador, producto de la reflexión sobre las causas de la derrota de 1940, se encontraba en falso con respecto al referente de equilibrio que prevaleció antes de la guerra (MULLER, 1990). Estaba centrado en torno a una voluntad de recuperar el retraso acumulado por Francia entre guerras a través de la modernización del aparato productivo y de la mentalidad de los franceses (KuISEL, 1984). Pero también estaba basado en un modelo de desarrollo específicamente francés que sobrevaloraba la acción estática y subvaloraba la iniciativa privada. Paradójicamente, esta representación del mundo que insistía en la necesidad de armar mejor la economía francesa frente a la competencia internacional, postulaba una relativa cerrazón del sistema económico y social, lo que dejaba un margen de maniobra al voluntarismo de las políticas públicas que caracteriza esta época.

El período que se abre con los años ochenta es, pues, un período de desfase de este referente modernizador, en torno al cual se ordenaban el conjunto de las políticas públicas sectoriales de Francia, en beneficio de un nuevo sistema de normas que privilegian la idea de mercado. Este nuevo referente de mercado no ha alcanzado aún el grado de formalización que goza el referente modernizador. Se basa en el reconocimiento de una norma internacional, la economía social de mercado, que se impone al conjunto de políticas públicas nacionales, habida cuenta de la apertura e integración creciente de la economía de los países industrializados, al menos en Europa. En Francia, esta norma condujo a la rearticulación de lo social y de lo económico, a una 
redefinición de la frontera público-privada y por fin a nuevas transacciones entre el centro y la periferia. Se trata por tanto de un trastorno del modelo político-administrativo francés a través del cambio en las formas de operar de las élites administrativas.

La crisis del modelo sectorial es en Francia una crisis de la economía (o de la sociedad) administrada, esto es, de un sistema que confiere al Estado el papel de motor en la gestión del desarrollo económico y social. Ello no significa, y es preciso aclararlo, el fin de las intervenciones públicas. Ello significa que, progresivamente, los objetivos de las políticas públicas serán definidos en el marco de un sistema abierto y estructurado por el referente de mercado. Esta evolución, que hemos descrito a través del ejemplo de la política agrícola, lo encontramos asimismo en otros sectores, como las telecomunicaciones, la aeronáutica... y, bajo otras formas, en los sectores sociales. Ello implica, en último término, la adecuación del expertise técnico de los grandes cuerpos de ingenieros que han marcado la originalidad del modelo francés, a no ser que sean capaces de llevar a cabo una reformulación de este expertise para adecuarla a la nueva norma de mercado.

Esta crisis de sectorialidad toma asimismo la forma de crisis de representación, con la pérdida de eficacia del corporativismo a la francesa. Se trata de adecuar el modelo de articulación de intereses basado en el monopolio de representación otorgado a los grupos profesionales verticales. Las dificultades actuales de la profesión agrícola constituyen un ejemplo caricaturesco. Así, la existencia de un continuum entre los ciudadanos y el Estado peligra con el debilitamiento de los corporativismos que juegan un papel de mediación cada vez menos importante, una de las manifestaciones más claras de esta evolución siendo la desindicalización.

Ahora bien, es preciso resituar la acción de las élites locales en este contexto de crisis de proximidad (entre el Estado y los ciudadanos). En efecto, el espacio local aparece hoy a la vez como un entorno potencial en el que reformular la sectorialidad para así superar los efectos perversos del corporativismo y como un entorno en el que se podrían reconstruir las relaciones de proximidad en las que los individuos pueden alcanzar un cierto control de la complejidad del mundo actual. Dicho de otra manera, el entorno local aparece hoy como un espacio donde la exigencia de eficacia puede coincidir con la exigencia de proximidad. El problema radica entonces en descubrir qué forma podría tomar esta relocalización de las políticas públicas (GRÉMION, MULLER, 1990).

No podemos hablar propiamente de una «vuelta» a lo local, dado que el entorno local al que nos estamos refiriendo tiene poco que ver con la Francia rural tradicional, la del prefecto y los notables. El entorno local del que se trata aquí es abstracto y no se puede identificar 
con el territorio tradicional. Por esta razón, la identidad de estos Gobiernos locales depende de las políticas públicas que sean capaces de llevar a cabo con el objeto de asumir el desarrollo económico local en conexión con los diversos empresarios locales. Esta evolución, que podría modificar de forma decisiva los modos de elaboración y de puesta en práctica de las políticas públicas en Francia nos lleva a plantear la emergencia de nuevas formas de mediación entre los ciudadanos y el Estado.

\section{BIBLIOGRAFIA}

BODIGUEL, M. (1986), Le rural en question, París, l'Harmattan.

COULOMB, P. (1990), «La cogestion: une nouvelle tentative corporatiste», en Coulomb, P.; Delorme, H.; Hervieu, B.; Jollivet, M., y LACOMBE, $\mathrm{Ph}$. , Les agriculteurs et la politique, París, ed. FNSP.

FAURE, A. (1989), «Le trousseau des politiques locales», Politix, núm. 7.-8. GrÉMION, C., y MULlER, P. (1990), «De nouvelles élites locales?», Esprit, septiembre.

HERVIEU, B. (1990), «L'agriculture en ruptures», Alternatives économiques, núm. 82, diciembre.

HouÉE, P. (1989), Les politiques de développement rural, París, INRA/ Economica.

JOBERT, B., y MULLER, P. (1987): L'Etat en action, politiques publiques et corporatismes, París, PUF.

JONES, Ch. O. (1970), An introduction to the study of public policy, Belmont, Duxbury press.

KAYSER, B. (1990), La renaissance rurale, París, A. Colin.

KEELER, J. T. S. (1987), The politics of neocorporatism in France, Nueva YorkOxford, Oxford Univ. Press.

KUISEL, R. (1984), Le capitalisme et l'Etat en France, París, Gallimard. MÉNY, Y., y THđEnIG, J. C. (1989), Politiques publiques, París, PUF, colección Thémis.

MUller, P.; GerbauX, F., y FAURE, A. (1989), Les entrepreneurs ruraux, París, l'Harmattan.

MULLER, P. (1990), Les politiques publiques, Paris, PUF, «Que sais-je?»

RÉMY, J. (1987), «La crise de la professionnalisation en agriculture: les enjeux de la lutte pour le contrôle du titre d'agriculteur», Sociologie du Travail, núm. 4.

Servolin, C. (1989), L'agriculture moderne, París, Seul, coll. «Points».

SCHMITTER, Ph. (1979), «Still the century of corporatism?», en SCHMITTER, Ph., y LEHMBRUCH, G., Trends toward corporatism intermediation, Londres, Sage.

WEBER, E. (1983), La fin des terroirs, París, Fayard. 